九州大学学術情報リポジトリ

Kyushu University Institutional Repository

Kinematic and Kinetic Gait Analysis of bilateral Knee Osteoarthritis and Its Effects on ankle and hip Gait Mechanics

Shai lendra Singh Chauhan

Faculty, Department of Mechanical Engineering G.L. Bajaj Institute of Technology \& Management, Greater Noida

https://doi.org/10.5109/4068617

出版情報：Evergreen. 7 (3)，pp.359-365，2020-09. 九州大学グリーンテクノロジー研究教育センター バージョン：

権利関係 : 


\title{
Kinematic and Kinetic Gait Analysis of bilateral Knee Osteoarthritis and Its Effects on ankle and hip Gait Mechanics
}

\author{
Shailendra Singh Chauhan \\ Faculty, Department of Mechanical Engineering G.L. Bajaj Institute of Technology \& Management, Greater Noida, India \\ E-mail: sschauhan3456@gmail.com
}

(Received March 17, 2020; Revised August 2, 2020; accepted August 23, 2020)

\begin{abstract}
The reason of this investigation was to evaluate the kinematic and kinetic gait analysis of persons who are suffering with bilateral knee osteoarthritis and with their healthy limb gait mechanics. Twenty subjects who are affected with the knee osteoarthritis (OA) with different age group, sex and body mass index were included in the study. This investigation aims at comparing the gait pattern of the hip joint and ankle joint between the knee OA and their other healthy limb gait mechanics. Kinematic and kinetic parameters were observed in depth with the use of Vicon gait analysis system. The motion range in sagittal, coronal and transverse plane, and peak joint moments of hip joint, knee joint and ankle joint were investigated. It was observed that speed of walking varies within the range of $0.99 \mathrm{~m} / \mathrm{s}$ to $1.02 \mathrm{~m} / \mathrm{s}$ for the subjects. The mean speed of walking for the subjects is $1.00 \mathrm{~m} / \mathrm{s}$. The stride length is measured in the range $1.02 \mathrm{~m}$ to $1.09 \mathrm{~m}$, averaging $1.05 \mathrm{~m}$. The pattern of the knee moments show a negative (flexion) internal moment at the joint indicating the line of action of the ground reaction forces (GRF) passing anterior to the knee joint during stance phase (upto $60 \%$ of walking cycle) and the ankle varus moment was observed 50\% higher in the knee OA affected subjects, thus creating a higher external extension moment at the joint. There is a significant increment in the GRF of the Knee OA patients in comparison to the normal person. This increment in the GRF is responsible to change the knee joint and hip joint gait mechanics. As the ankle moment is increased in association of Knee OA, much care should be given to the ankle joint and hip joint while treating patients with knee OA.
\end{abstract}

Keywords: evergreen; Biomechanics, knee osteoarthritis, Ground reaction force, Gait analysis

\section{Introduction}

Many people are affected with knee osteoarthritis (OA) due to extensive use of knee for multiple activities even in continuous standing posture ${ }^{1,2}$. Over a period of time the knee is wear down which depends upon the amount of usage of the knee and the side of knee used most often. Osteoarthritis affected middle age to elderly population and can damage the entire joint including cartilage, ligaments and bone. ${ }^{3)}$ Some people get affected in one knee, which is termed as unilateral OA. Whereas bilateral knee arthritis affected people are called both knee OA. Knee osteoarthritis is very painful and damages the entire mobility of the lower limb ${ }^{4,5)}$. Range of motion of knee OA patients is reduced and ground reaction forces are increased ${ }^{6,7)}$. Early diagnosis and suitable treatment to the patient can reduce the further damage of joint and improve the quality of life ${ }^{7}$. As the disease progresses, the risk for further complications like bone spur increases, impairing knee function, lack of ability to perform daily tasks, and disability, in the most severe cases. In the study of Al-Arfaj $\mathrm{A}^{8)}$ the radiographic OA was observed in $60.9 \%$ in females and $53.3 \%$ males. Side effect of OA is observed in more than
$50 \%$ persons beyond 65 years of age which includes approximately $18 \%$ women and $10 \% \mathrm{man}^{9)}$. Currently there is no cure for OA. ${ }^{10)}$ Gait speed changes after two years of bilateral total knee arthroplasty (TKA) and affects the kinematic and kinetic factors ${ }^{11,12)}$. The gait speed also depends on the muscular strength and age, decreasing as subjects becomes weaker and older. ${ }^{13-14)}$. Impaired neuromuscular forces and activation of the triceps surae muscle group affect the maximum walking speed ${ }^{15-16)}$. Factors like Gender differences influence walking speed and gait cycle consistency in community-dwelling older adults ${ }^{17-18}$ ). In general such patients are facing problems related to not only the muscle strength, but also to restore their normal gait pattern i.e. kinematics. Kinematics is equally important consideration as kinetics while examining osteoarthritis (OA) patients. In the kinetics of the OA patient gait assessment, the knee adduction moment is high and it contributes in the progression of arthritis ${ }^{19,20}$ ). A system model was developed to combine a number of observations on the mechanical, biological and structural components of OA to address the multifaceted nature ${ }^{21)}$. Many studies have been reported to assess the knee 
mechanics of OA patients. ${ }^{22,23,24,25)}$ However, very few studies have been reported on the secondary gait changes in the ankle and hip joints because theoretically hip, knee and ankle joints are functioning as a single kinematic/kinetic chain while walking ${ }^{26)}$. The ground reaction forces (GRF) have significant effect on the lower limb during stance phase of gait cycle ${ }^{27)}$. These forces can be bypassed by using suitable support system like knee braces. Knee braces fabricated with the use of reinforced composite material had improved its mechanical properties ${ }^{28)}$. This study is focused to the calculation of the hip and ankle joint mechanics of the knee OA patients.

\section{Methods}

A computerized gait analysis was performed for all knee osteoarthritis affected patents with the use of Vicon Motion Analysis system at Department of Physiotherapy and Rehabilitation, Research \& Referral, Army Hospital, New Delhi Cantt. The system was consisting of six infrared cameras with 60 fps frame rate and a force platform to measure kinetic parameters of the patients as illustrated in figure 1 . Lightweight refractive markers were placed on the body as per the Plug-in-Gait Protocol $^{29)}$.

A computerized workstation with software is used for data transfer, analysis, and storage. The methodology of the experiment is mainly divided into three parts, one is the experimental setup, second is the experiment conduction and third is the results analysis system. For the experimental framework a certain definable laboratory arrangement and appropriate setup of the gait analysis software was taken into consideration so as to make it more meticulous. The experiment was performed by collecting subject's anthropometric parameters first. The kinematic and kinetic data were recorded at $50 \mathrm{~Hz}$. Each subject was required to wear short trousers and walk barefooted.
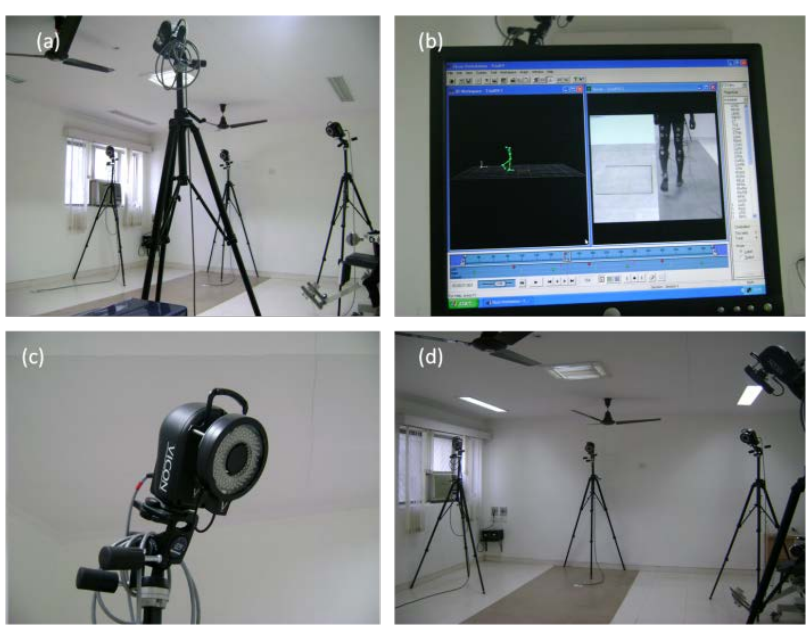

Fig.1: Motion capture system (Vicon Motion Analysis system at Department of Physiotherapy and Rehabilitation, Research \& Referral, Army Hospital, New Delhi Cantt.)
The recording techniques were initiated by taking anthropometric parameters of the subjects. The software allowed three dimensional IR cameras for recording the motion in the major joints of the lower extremities. The video recordings were taken as an input for kinematic assessment of the gait. Ground reaction forces (GRF) during stance phase were recorded with the help of two strain-gauged force platforms, dimensions (508 x 460 $\mathrm{mm}$ ). A systematic block diagram of gait analysis system is denoting the components used in the system and their inter connectivity itself indicating the complete method of motion analysis and data presentation.

\section{Results and discussions}

Basically three types of information are obtained from this study:

(a) Temporal and stride information of gait is obtained. These are the stride (cycle) time, stride length, average speed of walking, instant occurrence of foot flat, heel off, durations of stance and swing phase expressed as function of percent of walking cycle.

(b) Information from the kinematic analysis.

I. Range of motion (ROM) of the hip, knee and ankle joints in the longitudinal (along the plane of progression) and vertical directions.

II. Relative angular displacement, velocity and acceleration of knee and ankle joints with respect to angular displacement, velocity and acceleration of thigh.

(c) Information from kinetic analysis: Joint Moment/torque generated at hip, knee and ankle due to external forces.

\subsection{Temporal and stride measurements}

Characteristics and anthropometric data of knee OA in comparison to healthy subjects are presented in the Table 1. Twenty (Male-Female) subjects were taken for the study who are affected with the knee OA with the mean, age group 64.5(SD 5.4) years, height 152.8(SD5.6), and weight 62(SD 7.6). In total 35 (male-female) healthy subjects were participated for the calculation of reference gait parameters. These subjects have not reported any knee problem and no one had any prior diagnosis of Knee OA and any other problems. Their informed consents were taken prior to the clinical examinations.

Table 1. Characteristics and anthropometric data of Knee osteoarthritis and healthy subjects

\begin{tabular}{|c|c|c|c|}
\hline & $\begin{array}{c}\text { Knee OA } \\
\text { subjects } \\
(\mathrm{n}=20) \\
\text { Mean(SD) }\end{array}$ & $\begin{array}{c}\text { Healthy } \\
\text { subjects(n=35) }\end{array}$ & p-value \\
& Mean(SD) & \\
\hline Age (Years) & $64.5(5.4)$ & $63.8(3.1)$ & 0.226 \\
\hline
\end{tabular}




\begin{tabular}{|l|c|c|c|}
\hline Height $(\mathrm{cm})$ & $152.8(5.6)$ & $154.6(4.8)$ & 0.301 \\
\hline weight $(\mathrm{kg})$ & $62(7.6)$ & $57.4(7.4)$ & 0.003 \\
\hline BMI $\left(\mathrm{kg} / \mathrm{m}^{2}\right)$ & $27.2(3.6)$ & $26.4(3.4)$ & 0.002 \\
\hline
\end{tabular}

The mean weight of the healthy subjects was considerably less as compared to the Knee OA patents $(\mathrm{p}=0.003)$. Spatiotemporal data are shown in Table 2. It is observed that speed of walking varies within the range of $0.99 \mathrm{~m} / \mathrm{s}$ to $1.02 \mathrm{~m} / \mathrm{s}$ for the subjects. The mean speed of walking for the subjects is $1.00 \mathrm{~m} / \mathrm{s}$. Double support occurs at about $22.7 \%$ of the cycle with the range between $19.6 \%$ to $25.9 \%$ of cycle time. The single limb support occurs at about $38.7 \%$ of gait cycle on an average with a range of $34.7 \%$ to $42.7 \%$ of the cycle time. The stride length is measured about $1.05 \mathrm{~m}$ on an average $1.02 \mathrm{~m}$ to $1.09 \mathrm{~m}$. For fast walking speed the stride length is measured high and for slow speed this length is decreased.

Table 2. Average SpatioTemoral Parameters of knee osteoarthritis subjects

\begin{tabular}{|l|l|l|l|}
\hline Activity & $\begin{array}{l}\text { Without Knee } \\
\text { Osteoarthritis } \\
\text { (Left Leg) }\end{array}$ & $\begin{array}{l}\text { Affected With } \\
\text { Knee } \\
\text { Osteoarthritis } \\
\text { (Right Leg) }\end{array}$ & $\begin{array}{l}\text { Normal } \\
\text { Values }\end{array}$ \\
\hline $\begin{array}{l}\text { Cadences } \\
\text { (steps/min) }\end{array}$ & 99.2 steps/min & $98.6 \mathrm{steps} / \mathrm{min}$ & $113 \pm 12.4$ \\
\hline $\begin{array}{l}\text { 1st Double } \\
\text { Support (\%) }\end{array}$ & $25.9 \%$ & $19.6 \%$ & $11.9 \pm 2.16 \%$ \\
\hline $\begin{array}{l}\text { TOT Double } \\
\text { Support (\%) }\end{array}$ & $46.3 \%$ & $55.7 \%$ & $38.2 \pm 2.60 \%$ \\
\hline $\begin{array}{l}\text { Single } \\
\text { Support (\%) }\end{array}$ & $34.7 \%$ & $42.7 \%$ & $38.2 \pm 2.60 \%$ \\
\hline $\begin{array}{l}\text { Step } \% \\
\text { Length(m) }\end{array}$ & $0.64 \mathrm{~m}$ & $0.55 \mathrm{~m}$ & $0.62 \pm 0.08 \mathrm{~m}$ \\
\hline $\begin{array}{l}\text { Step Time } \\
\text { [s*100] }\end{array}$ & $0.65 \mathrm{~s}$ & $0.54 \mathrm{~s}$ & $49.9 \pm 2.24 \mathrm{~s}$ \\
\hline $\begin{array}{l}\text { Step } \\
\text { Width(m) }\end{array}$ & $0.17 \mathrm{~m}$ & $0.13 \mathrm{~m}$ & $0.25 \pm 0.23 \mathrm{~m}$ \\
\hline $\begin{array}{l}\text { Stride } \\
\text { Length(m) }\end{array}$ & $1.02 \mathrm{~m}$ & $1.09 \mathrm{~m}$ & $1.22 \pm 0.15 \mathrm{~m}$ \\
\hline $\begin{array}{l}\text { Stride } \\
\text { Time(s) }\end{array}$ & $1.21 \mathrm{~s}$ & $1.22 \mathrm{~s}$ & $1.06 \pm 0.12 \mathrm{~s}$ \\
\hline $\begin{array}{l}\text { Walking } \\
\text { Speed(m/s) }\end{array}$ & $1.02 \mathrm{~m} / \mathrm{s}$ & $0.99 \mathrm{~m} / \mathrm{s}$ & $1.17 \pm 0.23$ \\
$\mathrm{~m} / \mathrm{s}$
\end{tabular}

\subsection{Kinematic Analysis}

The convention used for the positive direction of linear displacement, flexion and extension of thigh and relative rotation at knee and ankle joints are shown in Figure 3. Six trials were taken for the OA affected subject. The angular displacement of thigh segments relative to vertical reference line, the relative rotation between thigh and shank axis at knee joint and that

between shank axis and the sole of foot at ankle joint are shown in figure 2 and figure 3 respectively. From figure 3 it may be noted that thigh rotation from its flexion position is about 16 to 20 degrees at heel strike. Thigh rotates flatly to maximum extension of about 10 to 12 degrees at about $48 \%$ to $53 \%$ of cycle time of walking, depending upon the speed of walking and height of subject. After this, thigh goes on rapid flexion which continues up to $80 \%$ of the cycle time during swing phase. At the end of stance phase of gait cycle the thigh becomes almost vertical. The magnitude of thigh flexion during walking is observed to be maximum during swing phase of walking (17 to 28 degrees).
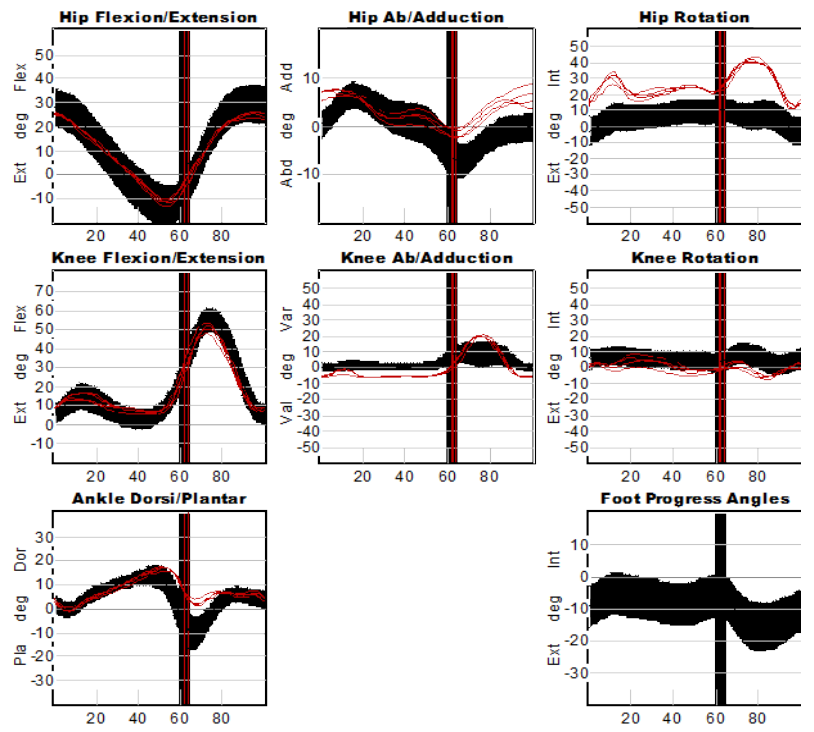

Fig. 2: Kinematics of without knee osteoarthritis affected subject during walking in sagittal, coronal and transverse plane.

(Flexion and extension are relative to \% of cycle)

The relative rotation at knee joint (figure 3) indicates that at heel strike, the knee flexion is almost zero. This flexion increases slightly during loading phase. The knee starts flexing with the heel off the ground and reaches about 40 degrees of flexion at the time of toe off. The peak values of knee flexion is reached at about $70 \%$ of the cycle time and at slightly late for slow speed of walking. The mean value of maximum knee flexion for five subjects is found to be 62 degrees. Speed of the gait is spontaneous measurement than physical examination when examine the arthritis patients ${ }^{30}$.

The relative rotation at ankle between the line parallel to foot sole and the axis of the shank is given in figure 3 . Using the convention of increase in angle from 90 degrees as plantarflexion at heel strike and this angle increases to about 8 degrees at foot flat position. After this the angle decreases during forward motion of body with foot flat on ground. The maximum dorsiflexion angle of about 13 degrees is reached at about $40 \%$ to $42 \%$ of gait cycle, coinciding with heel off position. 
After heel is off the ground, the ankle starts extending which continues up to $62 \%$ to $65 \%$ of walking cycle. In order to allow clearance between foot and ground during mid swing phase i.e, at about $80 \%$ of cycle time foot flexes and after which extends to allow the heel to prepare for next strike with the ground. The ankle plantarflexion during foot flat period while wearing shoes is reported in literature to be about 10 degrees, which is more than that obtained for bare foot walking in the present study. This is due to the fact that during walking with the shoes the foot rotates as a rigid body about the edge of the shoe sole at heel strike, but in case of bare foot walking the soft pad at the sole of the heel comes in contact with the ground which causes initial plantarflexion at heel strike.

Range of motion of the hip, ankle was found correlated with knee and smaller in the knee osteoarthritis affected subject (figure 3).
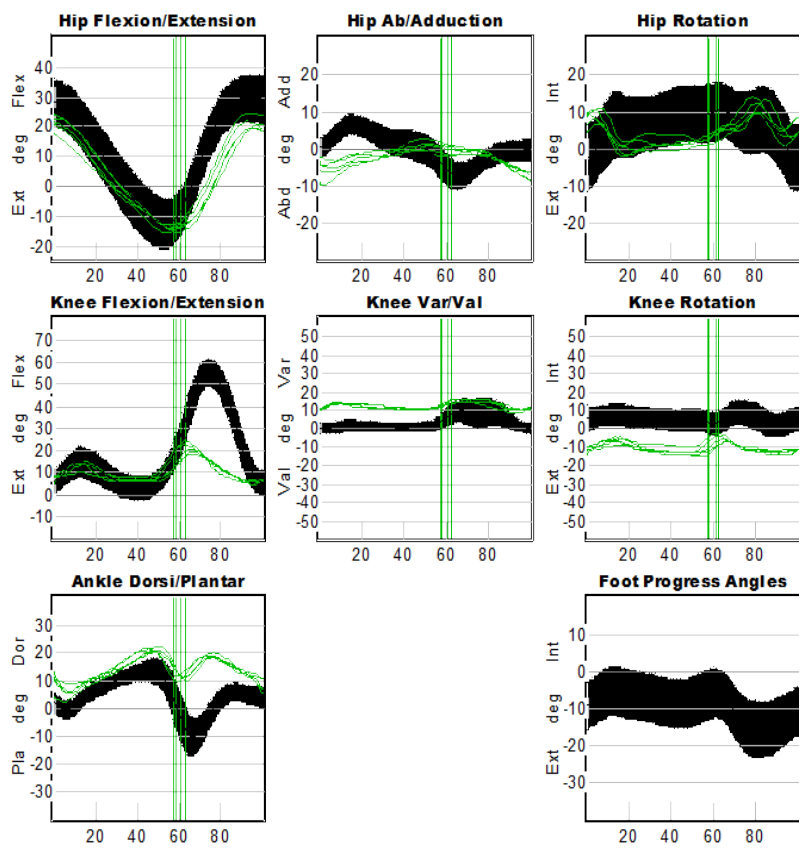

Fig. 3: Kinematics of knee osteoarthritis affected subject during walking in sagittal, coronal and transverse plane.

(Flexion and extension are relative to \% of cycle)

\subsection{Kinetic Analysis}

Joint reaction forces and moments developed at the hip, knee and ankle joints are due to external ground reaction forces (GRF), gravity forces and due to inertia of body segments ${ }^{31)}$ Kinetic data of without knee osteoarthritis and knee osteoarthritis affected subject is shown in figures 4 and figure 5 respectively. The convention used for the internal joint moments are indicated as follows:

3.4.1 Hip joint Moment: When the external forces create a flexion moment, the internal moment opposing this moment causes an extension moment and according to the sign convention of the analysis the extension moment at hip joint is a negative moment.

3.4.2 Knee joint Moment: When the external forces create an extension of the knee, the internal muscle moment opposing this moment causes a flexion moment which is a negative moment according to our convention.

3.4.3 Ankle joint Moment: When the external forces create a dorsiflexion the internal moment opposing this force is a plantarflexion moment and this is a negative moment according to sign convention.

The magnitude and pattern of moment variations at different joints are affected by several variables like the instantaneous values of GRF components and its distance from the point of application to the joint centre, linear and angular acceleration of the joints and segments and the weight of the different segments. Figure 4 shows the moments of Hip, Knee and ankle joints of Left side limb without knee osteoarthritis affected subject during walking in sagittal, coronal and transverse plane under study. The moments of hip, knee flexion/extension and ankle plantar/ dorsiflexion were calculated in the sagittal plane. Knee valgus/varus moment, Hip abduction/ adduction moment and ankle varus moment were calculated in the coronal plane as shown in figure 4.
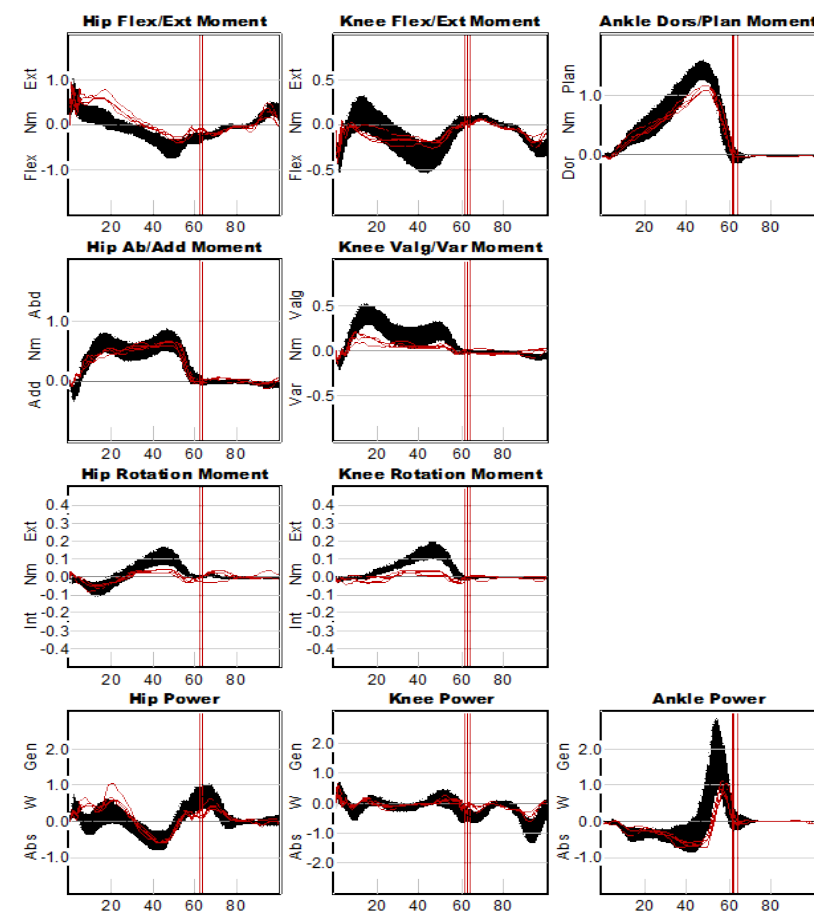

Fig. 4: Kinetics of without knee osteoarthritis affected subject during walking in sagittal, coronal and transverse plane.

The moments developed in saggital plane in the hip and ankle joints were also smaller in case of the knee osteoarthritis (OA) affected subject as compared to those without OA. Hip moment of knee osteoarthritis affected subject is shown in figure 5 . A negative peak value was measured at about $50 \%$ of walking cycle indicating maximum flexion moment developed at hip joint after 
the foot flat. When the major portion of the body weight is transferred to the foot on the ground from the other foot then the distance of the GRF about the hip becomes maximum. With the forward movement of the hip the distance of the GRF with respect to hip decreases and becomes negative, thus creating a positive peak corresponding to maximum hip flexor moment at the toe off instance. After toe off the gravity forces and inertia forces are contributing in the development of hip moment. At about $92 \%$ of the cycle time another negative peak is observed during swing phase when hip flexion is maximum prior to next heel strike. Consecutively, late stance ankle dorsiflexion and reduced late stance hip internal moments were also in progress.

The pattern of internal moments developed at the knee joints for Knee OA subjects is shown in figure 5. The pattern of the knee moments show a negative (flexion) knee joint moment. This is clearly indicating that the line of action of the ground reaction forces is passing anterior to knee joint during stance phase (up to $60 \%$ of walking cycle) thus creating an external extension moment at the joint. The moment variation at the ankle joint for Knee OA subjects is outward convex plantar-flexion moment up to $45 \%$ of walking cycle after which moment decreases rapidly and becomes almost zero at the end of stance phase as shown in figure 5 . The ankle moment is increased with the association of Knee OA therefore extra attention should be paid to the ankle joint when treating patients with knee OA
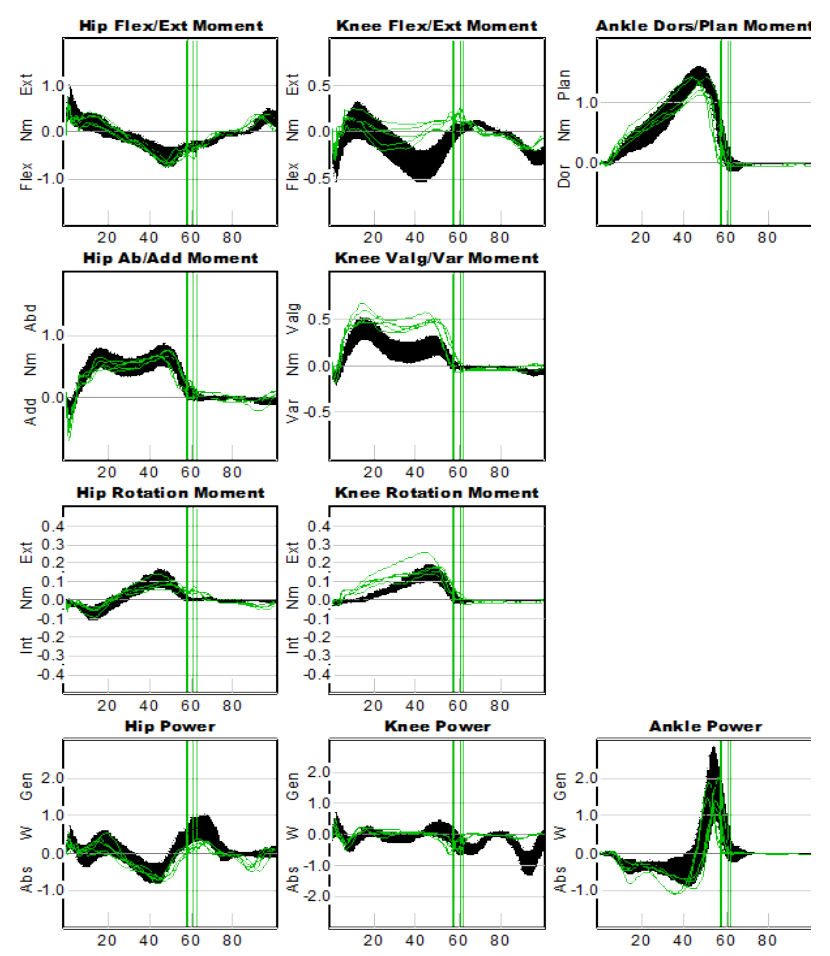

Fig. 5: Kinetics of with knee osteoarthritis affected subject during walking in sagittal, coronal and transverse plane.

Ground reaction forces (GRF) are used as an evaluation tool to analyse knee OA patients. ${ }^{32)}$ Gait results and GRF indicate the status of the OA patient.
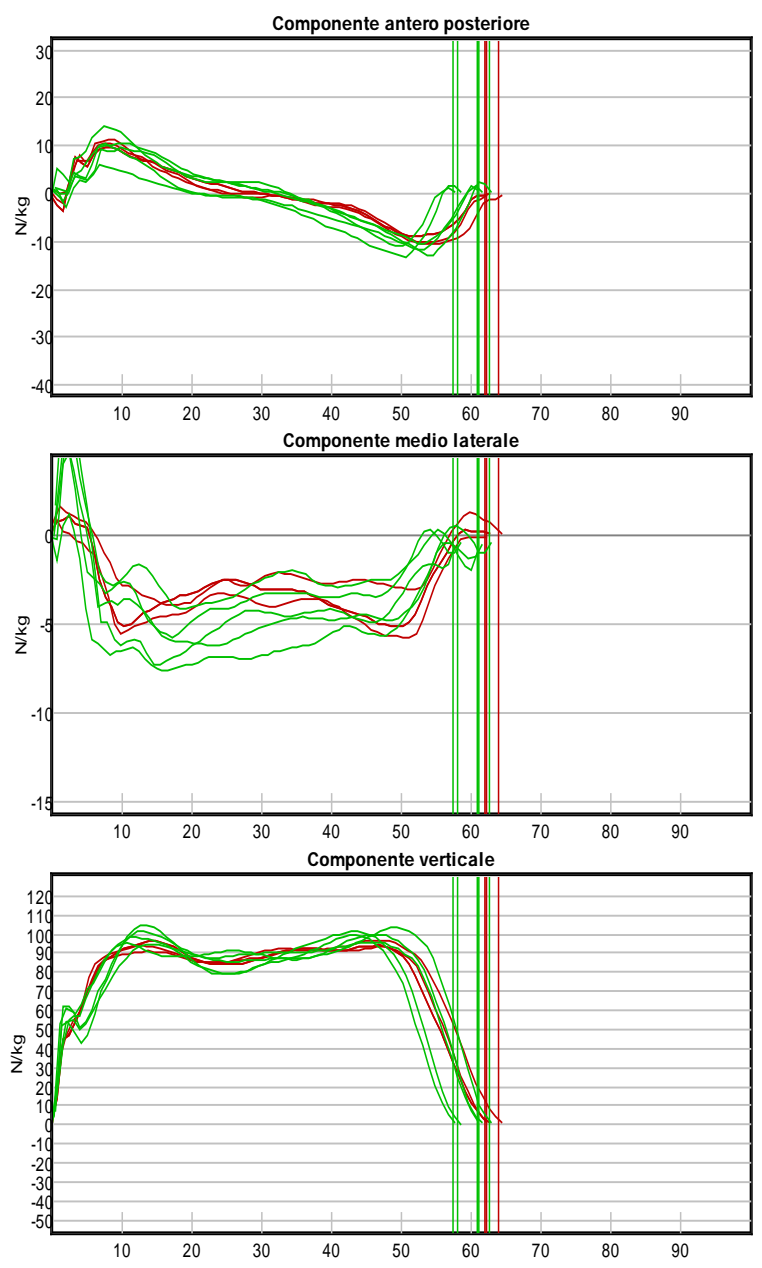

Fig. 6: Ground reaction forces of knee OA subject

The components of GRF are recorded during normal walking of the Knee OA subject and is shown in figure 6 . The subjects were allowed to walk on the platform with their own selected speed. Their walking trials were recorded successfully in the workstation. The components of GRF ie Antero-posterior (AP), Medio-lateral (ML) and vertical component (V) were analysed in two different peaks value as shown in figure 6. In the graph the AP component has a decreasing pattern whereas, ML component of the knee OA patients was increased significantly. It was observed that there is an increment in the GRF of the Knee OA patients in comparison to the normal person. This increment in the GRF is responsible to change the knee and hip joint gait mechanics. Therefore, GRF pattern can be used as an evaluation tool to observe the biomechanical changes in the knee OA patients. Hence this also assists in evaluating the effectiveness of the treatment.

\section{Conclusion}

Most significant outcome of this study was that range 
of motion of the hip, ankle was found correlated with knee which was smaller in the knee osteoarthritis OA affected subject. Therefore walking pattern of the affected limb can affect the entire functioning of the lower limb. The pattern of internal moments developed at the knee joints for Knee OA subjects is showing negative (flexion) internal moment in the kinetic results at the knee joint, indicating that the line of action of the ground reaction forces is passing anterior to knee joint during stance phase (up to $60 \%$ of walking cycle) thus creating an external extension moment at the joint. The range of motion of the Knee OA patients decreased and ground reaction force (GRF) increased significantly in comparison to the normal persons. GRF will directly affect the knee and hip joint biomechanics. Gait speed of the OA patients is decreased and it can be mathematically calculate as the product of stride length and cadence. Thus the stride length is an important parameter to calculate the speed differences. Kinematic and kinetic parameters play an important role for the direct calculation of Knee OA gait mechanics. In the current study it was observed that the hip flexion moment display a similar gait pattern because hip flexion is associated with the knee flexion. ${ }^{30)}$ Knee osteoarthritis OA has an adverse effect on the Range of motion, hip and ankle joints gait mechanics.

\section{Acknowledgements}

I am thankful to Dr. S. N Bhaduri, Physiatrist \& Rehabilitationist, and Department of Physical Med. \& Rehab. Army hospital (R \& R) New Delhi, India for providing the Gait laboratory and guidance for the gait analysis.

\section{References}

1) GA Hawker, EM Badley, R Croxford, PC Coyte, RH Glazier, J Guan, BJ Harvey, JI Williams, JG Wright "A population-based nested case-control study of the costs of hip and knee replacement surgery."Med Care. 2009 Jul; 47(7):732-41.

2) T. Vos, R. M. Barber, and B. Bell, "Global, regional, and national incidence, prevalence, and years lived with disability for 301 acute and chronic diseases and injuries in 188 countries, 1990-2013: a systematic analysis for the Global Burden of Disease Study 2013,” Te Lancet, vol. 386, no. 9995, pp. 743-800, 2013.

3) Shane Anderson A, Loeser RF. Why is osteoarthritis an age-related disease? Best Pract Res Clin Rheumatol. 2010;24(1):15-26. doi:10.1016/j.berh.2009.08.006

4) T. Neogi, "Te epidemiology and impact of pain in osteoarthritis,” Osteoarthritis and Cartilage, vol. 21, no. 9, pp. 1145-1153, 2013.

5) L. Murphy and C. G. Helmick, "Te impact of osteoarthritis in the United States: a population-health perspective," American Journal of Nursing, vol. 112, no. 3, pp. S13-S19, 2012.
6) J. Favre and B. M. Jolles, "Gait analysis of patients with knee osteoarthritis highlights a pathological mechanical pathway and provides a basis for therapeutic interventions,” EFORT Open Reviews, vol. 1, no. 10, pp. 368-374, 2016.

7) M. Henriksen, T. Graven-Nielsen, J. Aaboe, T. P. Andriacchi, and H. Bliddal, "Gait changes in patients with knee osteoarthritis are replicated by experimental knee pain,” Arthritis Care \& Research, vol. 62, no. 4, pp. 501-509, 2010.

8) GA Hawker. The Challenge of Pain for Patients with OA. HSS J. 2012;8(1):42-44. doi:10.1007/s11420-011-9254-8.

9) Al-Arfaj A, Al-Boukai AA. Prevalence of radiographic knee osteoarthritis in Saudi Arabia. Clinical rheumatology. 2002;21:142-5.

10) Anandacoomarasamy A, March L. Current evidence for osteoarthritis treatments. Ther Adv Musculoskelet Dis. 2010;2(1):17-28. doi:10.1177/1759720X09359889

11) C Brand, R Buchbinder, A Wluka, K Jones, D Ruth, $\mathrm{S}$ McKenzie, et al. Guideline for the non-surgical management of hip and knee osteoarthritis [with systematic review]2009 [cited 2011 Sep 17].

12) KM Jordan. et al. EULAR Recommendations 2003: An evidence based approach to the management of knee osteoarthritis: Report of a Task Force of the Standing Committee for International Clinical Studies Including Therapeutic Trials (ESCISIT). Ann Rheum Dis 2003;62(12):1145-55.

13) Ro, D. H., Han, H.-S., Lee, D. Y., Kim, S. H., Kwak, Y.-H., \& Lee, M. C. (2017). Slow gait speed after bilateral total knee arthroplasty is associated with suboptimal improvement of knee biomechanics. Knee Surgery, Sports Traumatology, Arthroscopy, 26(6), 1671-1680. doi:10.1007/s00167-017-4682-8

14) RW Bohannon (2008) Population representative gait speed and its determinants. J Geriatr Phys Ther 31:49-52

15) ML Callisaya, L Blizzard, MD Schmidt, JL McGinley, SR Lord, VK Srikanth (2009) A population-based study of sensorimotor factors afecting gait in older people. Age Ageing 38:290295

16) DJ Clark, TM Manini, RA Fielding, C Patten (2013) Neuromuscular determinants of maximum walking speed in well-functioning older adults. Exp Gerontol 48:358-363

17) I Hayashida, Y Tanimoto, Y Takahashi, T Kusabiraki, J Tamaki (2014) Correlation between muscle strength and muscle mass, and their association with walking speed, in community-dwelling elderly Japanese individuals. PLoS One 9:e111810.

18) $\mathrm{W}$ Inoue, $\mathrm{T}$ Ikezoe, $\mathrm{T}$ Tsuboyama, I Sato, KB Malinowska, T Kawaguchi et al (2017) Are there diferent factors afecting walking speed and gait cycle variability between men and women in community-dwelling older adults? Aging Clin Exp Res 29:215-221 
19) K Matsuda, S Ikeda, M Nakahara, $T$ Ikeda, $R$ Okamoto, K Kurosawa et al (2015) Factors afecting the coefcient of variation of stride time of the elderly without falling history: a prospective study. J Phys Ther Sci 27:1087-1090.

20) A. M“undermann, C. O. Dyrby, and T. P. Andriacchi, "Secondary gait changes in patients with medial compartment knee osteoarthritis: Increased load at the ankle, knee, and hip during walking," Arthritis \& Rheumatology, vol. 52, no. 9, pp. 2835-2844, 2005.

21) D. Schmitt, A. Vap, and R. M. Queen, "Effect of end-stage hip, knee, and ankle osteoarthritis on walking mechanics,” Gait \& Posture, vol. 42, no. 3, pp. 373-379, 2015.

22) Kenton RKaufman "Gait characteristics of patients with knee osteoarthritis" Journal of Biomechanics Volume 34, Issue 7, July 2001, Pages 907-915

23) un Sun, Yancheng Liu, Songhua Yan, Guanglei Cao, Shasha Wang, D. evin Lester, Kuan Zhang "Clinical gait evaluation of patients with knee osteoarthritis Gait \& Posture, Volume 58, 2017, pp. 319-324

24) Chris A McGibbon, David E Krebs "Compensatory gait mechanics in patients with unilateral knee arthritis. The Journal of Rheumatology Nov 2002, 29 (11) 2410-2419;

25) TP Andriacchi, J Favre, JC Erhart-Hledik, CR Chu. "A systems analysis of knee osteoarthritis reveals new insights into the pathogenesis of the disease”. Ann Biomed Eng 2015;43:376-387.

26) J. L. Astephen,K. J.Deluzio, G. E. Caldwell, andM. J. Dunbar,"Biomechanical changes at the hip, knee, and ankle joints during gait are associated with knee osteoarthritis severity,"Journal of Orthopaedic Research, vol. 26, no. 3, pp. 332-341, 2008.

27) SS Chauhan, "Kinematic and kinetic analysis of knee joint during squatting”, IOP Conference Series: Materials Science and Engineering Volume 691, 2019. doi:10.1088/1757-899X/691/1/012020

28) Nagendra Kumar Maurya, Vikas Rastogi, Pushpendra Singh "Experimental and Computational Investigation on Mechanical Properties of Reinforced Additive Manufactured Component”, EVERGREEN Joint Journal of Novel Carbon Resource Sciences \& Green Asia Strategy, Vol. 06, Issue 03, pp207-214, September, 2019.

29) VP Guide. Foundation notes revision 2.0 March 2010: For use with Plug-in Gait Version; 2010.

30) G Abellan van Kan, Y Rolland, S Andrieu, J Bauer, O Beauchet, M Bonnefoy et al (2009) Gait speed at usual pace as a predictor of adverse outcomes in community-dwelling older people an International Academy on Nutrition and Aging (IANA) Task Force. J Nutr Health Aging 13:881-889

31) J Bjerke, F Ohberg, KG Nilsson, AK Stensdotter (2016) Walking on a compliant surface does not enhance kinematic gait asymmetries after unilateral total knee arthroplasty. Knee Surg Sports Traumatol Arthrosc 24:2606-2613.

32) Garrido-Castro J, Gil-Cabezas J, Perez-Guijo V, et al. "Ground Reaction Forces in Patients with Knee
Osteoarthritis after Intra-Articular Treatments Annals of the Rheumatic

Diseases” 2014;73:746-747. 